\title{
The Black Tea Industry in East Africa: History, Culture, Trends, and Opportunities
}

\author{
Sahim Abdalla Juma, Ph.D. Public Administration, \\ University of Science and Technology of China, School of Public Affairs \\ No.96, JinZhai Road Baohe District, Hefei, Anhui, 230026, P.R.China. \\ "Water is the mother of tea, a teapot its father, and fire the teacher." Chinese Proverb
}

\begin{abstract}
Since its introduction in the $18^{\text {th }}$ century in Malawi, black tea has become one among favorite tea in Africa especially in East Africa. Historically black tea was introduced in East Africa by colonial rulers who came to settle in this part of Africa and were much fascinated by fertile land and good weather for plantations. The Author of this article has analyzed the history, culture and new economic trends of black tea in East Africa from various online and offline sources and presented his findings and way forward. The Author thinks that the economic benefits of black tea are very high and necessitate the need to develop all processes from tea plantations, grading, packing, and export so that the maximum economic benefits can be exploited. Regarding new trends of black tea, the author proposed the black tea farmers, processors and traders from East Africa to learn from their counterparts in China. Chinese tea industry has always been considered as the most developed one. This study can help Governmental Agricultural officers, policymakers, and tea industry stakeholders and tea enthusiasts to develop the black tea industry further in East Africa.
\end{abstract}

Keywords: Black tea, East Africa, Tea Culture, Wholesale tea, Chinese Tea, Tea Benefits, Tea Economy

DOI: $10.7176 / \mathrm{JESD} / 10-6-19$

Publication date:March $31^{\text {st }} 2019$

\subsection{Introduction}

East Africa, the region some refer as the "cradle of mankind" is a prominent share of the African region. As denoted by the name, the countries that are located in the eastern part of Africa comes under the demarcation "East Africa."

The region consists of two distinct geographic regions: firstly, the eastern portion of the African continent as seen in figure 1 includes countries such as Kenya, Tanzania, Uganda and the other part commonly known as the Horn of Africa, which includes countries such as Somalia, Djibouti, Eritrea, and Ethiopia.

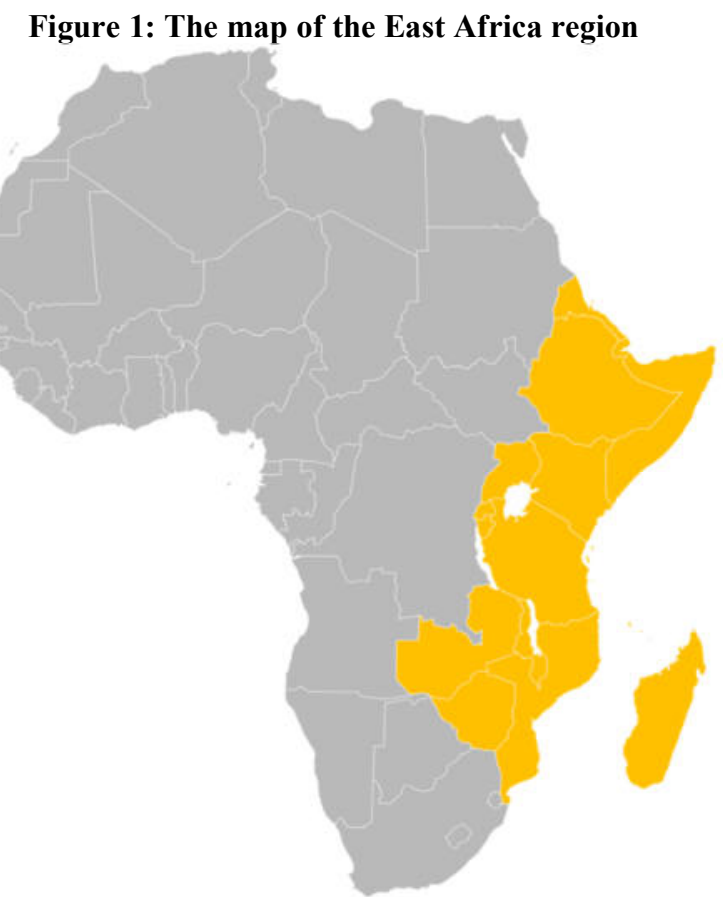

Source: Wikimedia Commons 
For thousands of years of human history, East Africa as a beautiful region of the planet has been invaded by many due to the abundant resources inherited by the countries. Looking into history, it features the rise and fall of mighty kingdoms and chiefs, robust trade networks including the slave trade and the signs of colonialism.

When it comes to the colonialism, history told us that there were interventions from nations such as Portugal, Britain, Oman, Germany, France, and Italy.

The ultimate goal of all these invasions among others was to acquire the fertile agricultural lands that are ideal for large-scale agriculture especially commercial crops such as coffee and tea. History can confirm that Tea was an experiment brought by the British rulers in East Africa, but it has helped these nations in numerous ways to sustain their economies.

Today, tea has become a big business in East Africa. It has rooted in the lives of many households (Traditional Peoples drink black tea every morning before work and evening after work) and has become the lifeblood of people and the economy. The region has got the grip of the rich growing traditions and the art and science of crafting the much-demanded tea brew all over the world.

There are many teas producing countries in the East African region including Kenya, Uganda, Rwanda, Tanzania, Burundi, and Ethiopia. The tea types and brands that are grown in East Africa have become a vital ingredient in many healthy and flavorful blends all over the world.

\subsection{Common East Africa Tea Brands}

TATEPA, KATEPA, Chai Bora are among the familiar tea brands in East Africa. This tea is packed and branded by well-known, experienced tea companies in East Africa.

\subsection{Tea History in China}

There are many teas producing countries in the continents of Asia and Europe, as seen in figure 2 China has remained the largest tea producing country in the world in the number of metric tons (Perfect Insider, Nisha 2015).

As the myth goes by, the origin of tea as an official beverage is remaining unknown, but different sources can confirm that China was the first part of the world to use tea as drinking beverage 5,000 years ago. The sources say that "Camellia Sinensis" was the first plant to be used as Tea.

Figure 2: Top 10 List of Tea Exporting Countries

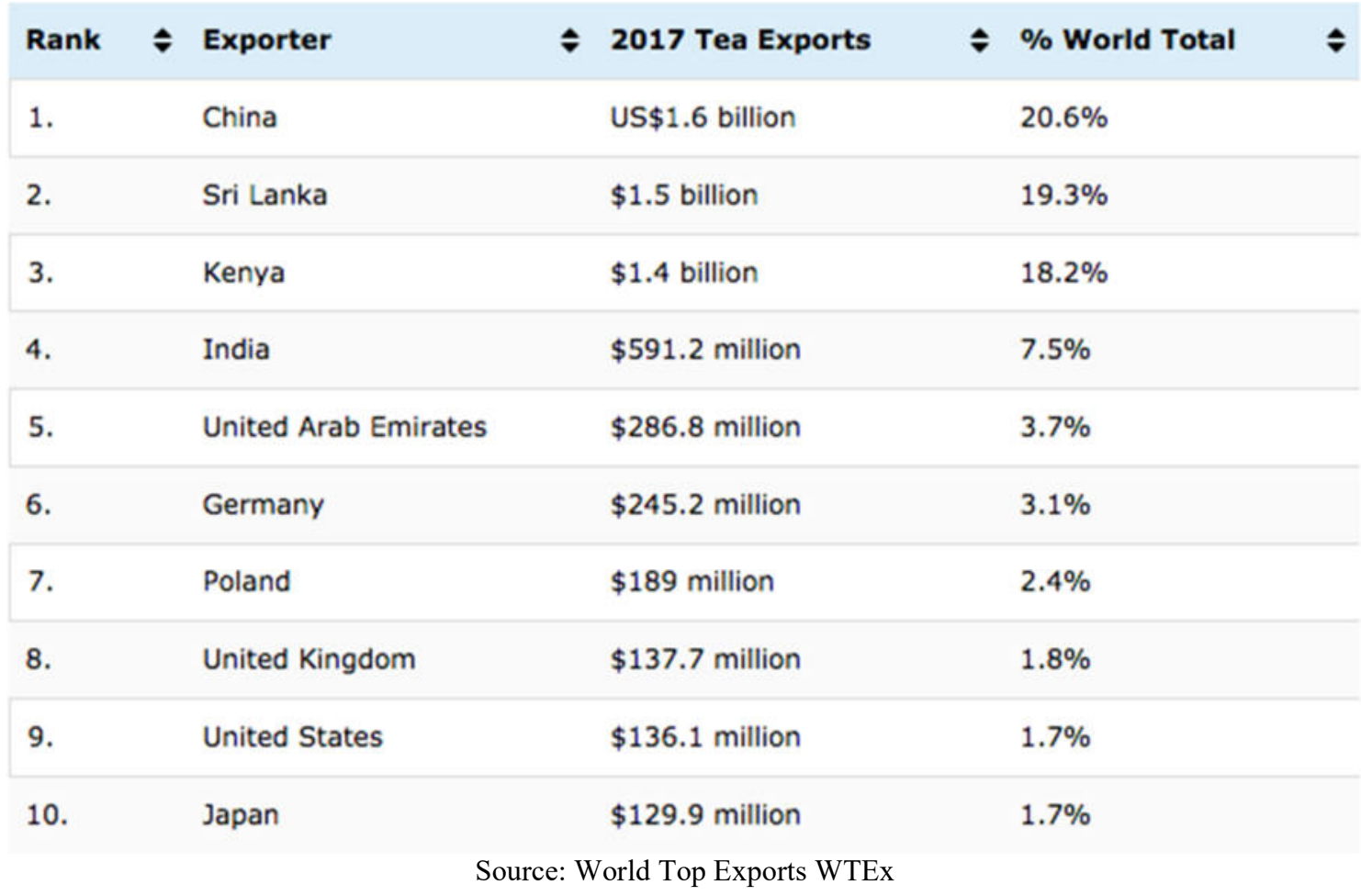


"Shennong" (A name translated as Divine Farmer) Ancient Chinese Emperor is believed to be the most famous legend who mastered how to drinking tea which was also a herbalist and a farmer as well. This tea master had vast knowledge about tea science in those earlies days who also introduced boiling water techniques to make it safe around 2737 B.C.

His behavior of boiling water made one day the tea leaves to accidental slip in hot water which made the tea test more enjoyable, and this is how the tea boiling techniques were believed to have started.

At those earliest days, there were also believes that "Wan Tu" was the true discoverer of tea. This cruel man was believed to live in the Southern part of China. The myth tells that, because of drinking tea behaviors this man changed from cruel and evil to kinder and very gentleman.

Another theory suggests that "Bodhidharma" who was Buddhist was also a tea discoverer. He is believed to travel to China from India and use tea in his meditation and Buddhism practice.

\subsection{History of Tea in East Africa}

History of East African tea industry goes back to the year the 1890s where like in many other teas growing countries, British planters started experimenting tea in one of their African colonies, Malawi. This was successful experimentation, and also it was regarded as one of the safer moves for British, due to the fertile growing conditions and also the region was expected to remain as a British colony for many years to come.

On the other hand, they had begun to lose their profits from other colonies like Sri Lanka, due to some crop diseases spread around the country. From Malawi, it started to expand into other countries like Kenya, Tanzania, Rwanda Burundi, and Zimbabwe as well. The CTC (cut, tear, Curl) technique of tea manufacturing was introduced to the East African countries by the year of the 1930s, and this was a real turning point of the East African tea industry. The reason was that world demand for smaller tea particles was at a rising trend due to the solid brew resulted by smaller tea particles.

Hence with the CTC type tea production, the East African countries were able to produce much smaller tea particles, and this technique was ideal to bring out the original strong flavors of east African tea. It was an excellent ingredient for the production of tea bags as well. Soon, the teas produced in the area were met with a demand from all over the world especially from the European region as an essential ingredient of the English breakfast tea.

Many of these countries started to get their independence starting around 1060's, and from there the tea industry was under the custody of local authorities. Some countries like Uganda and Tanzania followed nationalization strategy and faced many other political issues and as a result of today facing a declining trend.

Malawi, on the other hand, is facing problems related to limited in expansion and again on a declining trend. In contrast, Kenya is on a growth strategy with the considerable expansion and today has become the third largest tea producer in the world.

The east African tea industry has achieved an overall growth since its inception, and it is important to notice that there have been two auction centers to sell the produce of the region. The Mombasa tea auction being the main auction center was initiated in 1965 in Nairobi at a tiny scale, however, had to shift into Mombasa by 1969 with the expansion of trade.

The Mombasa tea auction currently sells the offerings from Kenya, Uganda, Tanzania, Rwanda, Burundi, Democratic Republic of Congo, Malawi, Madagascar, Zambia, and Zimbabwe. This is now the only auction center in the world trading teas from more than one country. The Malawi auction center, on the other hand, was initiated in the 1970s in Limbe, Malawi. The most common tea in East Africa is Black Tea.

\subsection{Black Tea Harvesting Techniques}

After the tea leaves have been picked, black tea leaves are laid down so that they can dry. When the black tea leaves have been dried, they are fermented for two hours. The leaves are later heated to remove the moisture.

There are various factors to determine the quality of black tea, The overall it mainly depends on soil condition and the expertise of the grower. The black tea best grows in a warm area of high altitudes of about 3,000 to 8000 feet so that it can grow more slowly that will result into the best flavor. The rain season is also significant for the tea leaves to survive. 


\subsection{Black Tea Grading}

The excellent Grading results may be from the reason of proper plantation techniques, a region where it was harvested, good location of storage, temperature, and packaging. The size of the leaf is said of high importance in assigning the grade of black tea. To have a better size of the leaf is highly depending on how tea has been harvested and how has been processed. Crush, Tear, and Curl (CTC) are the primary method for processing black tea.

There is terminology for best tea grade is known as Tippy Golden Flowery Orange Pekoe. This tea of tea is of high grade because the tea leaves are hand-picked and carefully processed. On the other hand, it is worth to note that, The process of grading green tea is different compared to black tea grading. The Grading of green tea considers its overall taste and quality. The green tea grading also depends on where it was grown and harvested and the types of tea leaves.

The tea grading is necessary because the more knowledge you have about tea grading system, the more enjoyable it will become. The understanding of tea grades has been said to increase tea drinking habits.

\subsection{Health Benefits of Black Tea}

Black tea has many benefits which including; drink black tea because of its unique taste, medicinal benefits, boosting energy or as a beverage. This type of tea has always been graded to choose from the best tea leaves that have maximum benefits. The grading variation includes color, flavor or smell.

Black tea has long believed to have many medicinal benefits including less problem with cancer, heart diseases or other illness. Scientifically it has been proved that people who drink black tea are healthier than those who do not, Black tea is also full of healthy substances called polyphenols. Polyphenols are antioxidants that can help protect your cells from DNA damage (WebMD).

Drinking black tea has also been said to help patients with asthma diseases, increasing evidence hints that the antioxidants in black tea may reduce atherosclerosis (clogged arteries), especially in women. It may also help lower the risk of heart attack and cardiovascular disease. (WebMD).

The scientists have also found out that, black tea can increase memory, improve the human mental capacity among other benefits. Black tea consumption speeded the performance, improved memory, reduced number of errors in the various cognitive tasks. Our results further showed that even in a small volume of black tea consumption can speed up cognitive processing (Rizwan, A., Zinchenko, A., Özdem, C. et al. Clin Phytosci).

\subsection{Types of Black Tea}

There are varieties of black tea, "Keemun" is the highest quality of black tea type. The aroma of this type of tea made it stand out of the crowd. "Keemun" tea can be mixed with milk and sugar or without and it still tastes better.

"Darjeeling" is another Indian black tea which is very famous in the world for its very delicate taste. India is one among the world best tea growers and processors. Indian black tea brands come with various taste and flavor which includes ginger and cinnamon, or cloves mixed tea.

India also brews another popular tea flavor which is known as "Nilgiri." The process of brewing this type of tea requires some expertise in order to brew it in the right flavor. Another type of great less spicy tea is called "Assam." This black tea type is best known for its rich taste.

"Lapsang Souchong" is believed to be among the best Chinese black tea. This tea has an unusual smoky flavor which made it taste better. "Yunnan tea" with pepper flavor is also among the well know Chinese black tea.

Some of the worlds know tea flavor is that are grown in Kenya, East Africa. This tea brand has been exported to many parts of the world to be used as a beverage. Another well known flavored tea is that from Nepal. This type of tea is of high flavor because it is grown in the base of Mount Everest in Nepal.

The author believes that black tea is different from other types of tea because of its distinctive flavor. Once you have tried the black tea flavor, you might develop the tendency of drinking black tea more than another type of teas.

\subsection{Trends of the black tea industry}

Similar to many other countries which started black tea cultivation during the British colonized period, the east African black tea trade still follows the original mode of production (CTC) as well as the traditional way of trading and exportation, see figure 3 . 


\section{Figure 3: Tea Production Process}

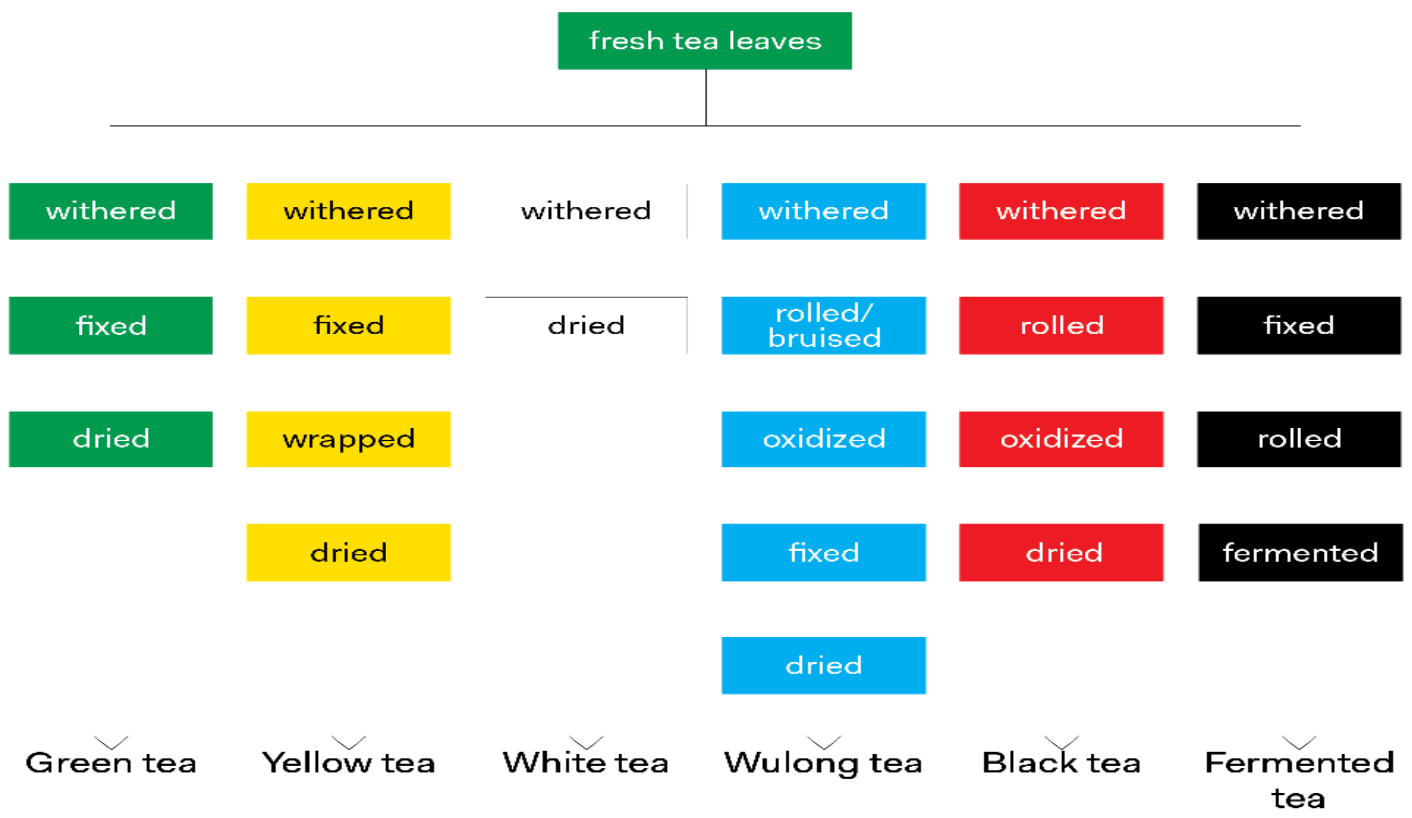

Source: Tea Processing Chart by Tony Gebely

According to the trade reports (USDA Foreign agricultural service report, 2013) the majority of black tea products, especially the products of the large producers like Kenya, are still exported as a bulk commodity and produced through the traditional CTC technique.

However, it is important to note that the Black tea industry is an essential component in the east African economy. The region has achieved around 6\% GDP growth from 2010 to 2016, and when looking into details, Black tea has been an imperative contributor. As reported in Socio-cultural impact in East Africa report (2017) "Kenya's agricultural sector has been the single most significant driver of East Africa's GDP growth.

The tea sector contributed 22\% of the East Africa region's overall GDP growth and more than half of growth in Kenya. Kenya's National Bureau of Statistics attributes this to growth in value addition for the horticulture and black tea sectors".

Even though the region has achieved economic growth through the agriculture sector, it is vital to capitalize on global opportunities through the better recovery of commodity prices.

When it comes to the black tea sector, the global consumption patterns are rapidly changing and can be seen as opportunities for producers. Identifying and capitalizing on these opportunities is a must for the long-term survival of this trade. Addressing into these needs, some attempts have been initiated by the ETTA (East African Tea trader's association) and the governments, and these can be seen as new trends in the tea industry.

Trends towards possible value additions such as manufacturing black tea bags and investing in the production of instant black tea and tea extracts can be seen as a growing sector in the East African region.

For example, the instant black tea powders and tea extracts are extremely popular all over the world, and many multinational companies have invested in these areas, especially in large producing countries like Kenya. There are various processes involved in the commercial production of instant black tea include the blending of black tea leaves, hot water extraction, aroma recovery, soluble solids concentration, and aroma restoration and dehydration. (someswararao \& srivastav, 2012).

On the other hand, there is also a trend to produce iced black tea products and ready-to-drink black tea products in order to cater to the growing world demand for these products. The region also has focused on moving into other 
styles of production where much value can be added to the final product such as green tea production, orthodox style manufacturing, white tea or oolong tea production. Further, there is also a focus on gaining brand awareness regarding country of origin as well.

On the other hand, while black tea continues to increase in popularity, other alternatives and ingredients such as herbs and fruits can be seen as an emerging trend due to the added benefits of these ingredients. For example, herbs such as Rooibos are an equally popular product of the African region. Therefore, the producers can look for ways of combining these ingredients as a way of value addition.

Specialty even for traditional black tea production, new trends related to various compliances such as organic certification, fair-trade certification, etc. can be seen as a new trend in the east African tea industry. (Euromonitor International report, 2017). Especially these certifications and compliance are essential when exporting to some European countries.

\subsection{The Tea Culture}

Tea culture was introduced to the East African region since the first introduction of tea in 1880 to Malawi. Since then this became a part of the society regarding employment opportunity as well as a part of the culture.

In general terms tea culture can be identified as the way of tea is prepared and consumed by different communities. In most cases, these traditions are passed from one generation to another and an essential component of regular life. When it comes to the tea culture in East Africa, some examples can be taken from countries like Kenya where the large-scale tea production takes place.

Most of the tea drinking habits in Kenya resemble some similar elements to British tea culture. For example, the black tea is served with added milk and sugar resembling the English breakfast tea culture of Europe. However, this type of thick tea is most famous as an afternoon tea in east Africa and usually accompanied by a simple snack.

In addition to that, there is also a trend to consume just black tea or "strung" as the afternoon tea and some known to take additives like ginger or mint along with the tea.

Pure black tea is prepared by steeping black tea leaves in hot water; however, it is also visible that most of the East African nations love to consume their tea with other additives like spices.

One example is "Chai ya Tangawizi" or Kenyan Ginger Tea. Simmering black tea leaves prepare Kenyan ginger tea with milk, ginger, cinnamon, cardamom, and cloves and making it to creamy and warming mixture of spicy tea. This is known to be an ideal beverage for cold weather.

However, there are many shreds of evidence that east African consumers are moving beyond the traditional forms of consumption. This option includes emerging trends such as fair-trade and organic tea.

As reported by the executive brief of Agritrade, (2013) "According to preliminary market research, out of a sample of consumers questioned, $86 \%$ of Kenyan consumers would look out for the Fair-trade mark when shopping, while $73 \%$ would be prepared to pay extra for a product with the Fair-trade label tea". A combination of green tea and mint is also known to be a popular tea custom in the African region.

\subsection{Key players of the industry in East Africa}

When considering the east African region, there are many black tea producing countries as a part of the economy. However, countries like Kenya, Malawi, Uganda, and Rwanda can be identified a few of the key players of the industry.

Figure 1 Share of African black tea production, $2012(\%)$

\subsection{Kenya}

Kenya can be seen as the giant in east African tea trade. Moving into tea can be seen as one of the most strategic moves in Kenyan economy as today, the tea industry has made Kenya's mark on the world map. According to the literature, tea was introduced to Kenya by a European Planter G. W. L. Caine in 1903. (Tea \& Coffee industry report 2005). Brooke Bonds in 1924 started the first commercial tea estate, and since then, the industry commercialization has started. The country has taken the industry forward for more than 80 years as a commercial crop. 
Today Kenya has become the third largest tea producer in the world with approximately 439 million $\mathrm{kg}$ production in 2017 (Tea status report, 2017) and also has rated as the largest exporter in the world. With these advancements, naturally, the tea industry has become an essential component of the Kenyan economy with approximately 129 billion shillings of export earnings in 2017 (Reuters, 2017).

The country contributes $18.2 \%$ of the total global tea exports (The World Factbook, 2018) and over 3 million Kenyans, approximately $10 \%$ of the population are being actively engaged with the tea industry today. These facts indicate the importance of the tea industry to the country's economy.

Mombasa tea auction is also one of the most critical factors for the Kenyan tea industry as this serves as the critical sourcing center in East Africa, trading the tea produce of more than ten nations. The country also has a reasonably structured tea supply, and value chain often interacts with organizations like KTDA (Kenya Tea Development agency) and ETTA (East Africa Tea Trade Association)

\subsection{Malawi}

Malawi is known to be the first country of the region to grow tea under the British ruling. Malawi's tea industry dates back to 1891 when a Scottish planter named Henry Brown settled there after losing all of his coffee plantations in Sri Lanka due to a disease (The Tea Detective).

Since then the Malawi tea industry has grown and today have become a crucial component of the country's economy, see figure 4. Malawi is the second largest tea producer and exporter in Africa after Kenya. Tea ranks third regarding export value after tobacco and sugar (FAO, 2014).

\section{Figure 4: Major Exports of Malawi (2016)}

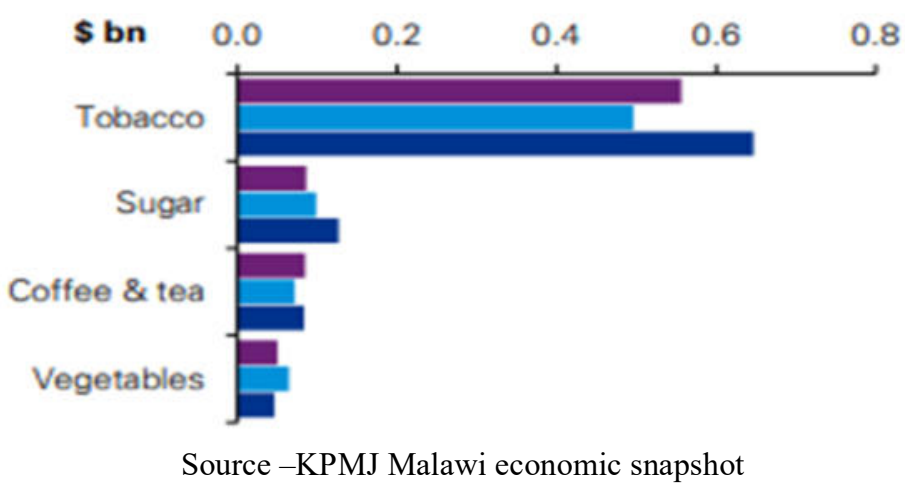

The country produces a majority of black tea followed by a smaller amount other verities and the tea produce is mainly exported to destinations such as Europe, Asia, and North America. Malawi contributes to approximately $10 \%$ of the tea production in Africa with around 48,486 MT production.

Like many other East African tea producers, Malawi also exports the majority of its products in bulk form as they do not have the capital to enter into the consumer market.

\subsection{Uganda}

Uganda is another vital member of East African tea producers, and the country has started its commercial-scale tea plantation around the 1900s. Similar to many other countries in the region, Tea is an essential commodity for Uganda as well. 
Figure 5: Uganda's Tea Commodity Value Chain

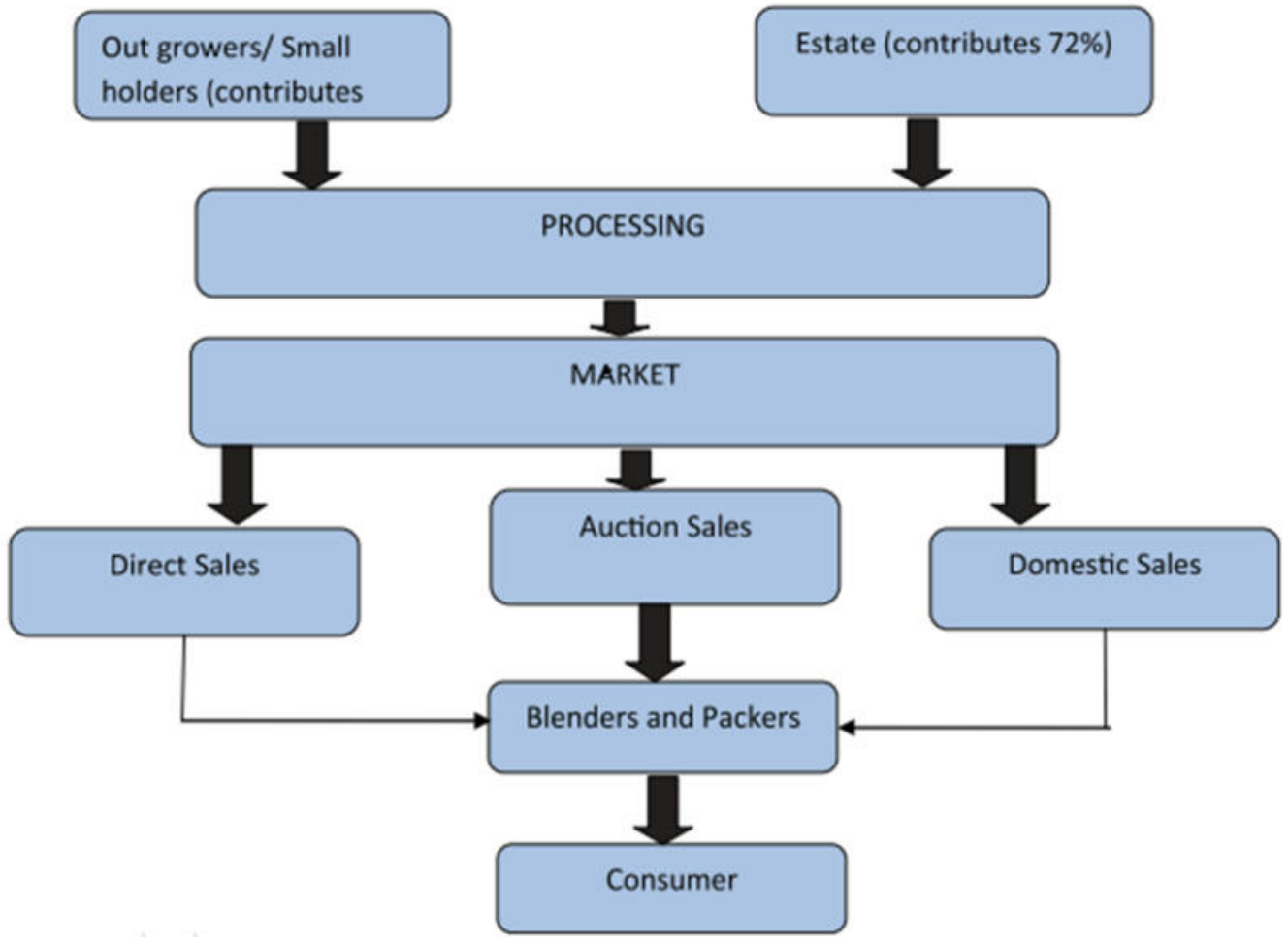

Source: MAAIF (2012)

Tea is considered the third largest agricultural commodity by value (EPRC research, 2014). The country earns around \$90-100 million through the tea trade, and the export volume reached 421 million kilograms in 2018 (EPRC research, 2014).

This trade is known to support over 60,000 people annually, and the industry is envisioned as a tool to fight poverty through its ability as a source of employment to households, especially in rural areas (Daily Monitor, 2018).

The country still has not focused much on consumerization or value addition of its produce; hence over $90 \%$ of Uganda's produce is sold in bulk form, mainly through the Mombasa auction, see figure 5. The major export destinations include Europe, Middle East, Russia, and America.

\subsection{Rwanda}

Teas from Rwanda are well known for its bright color and strength thus these teas have been able to capture its place on traditional English breakfast tea. Tea growing in Rwanda started around 1952 and is continued up to today with over 30,000 smallholdings and 60,000 households making a living out of tea farming.

The teas from all around the country are sold by private contract and through the auctions in Mombasa and Limbe. As shown in figure 6 Coffee, tea, and minerals dominate Rwanda's merchandise exports, accounting for more than 90\% between 2007 and 2012 (Rwanda infographics report 2012) 
Figure 6: Rwanda Export composition as a total of exports

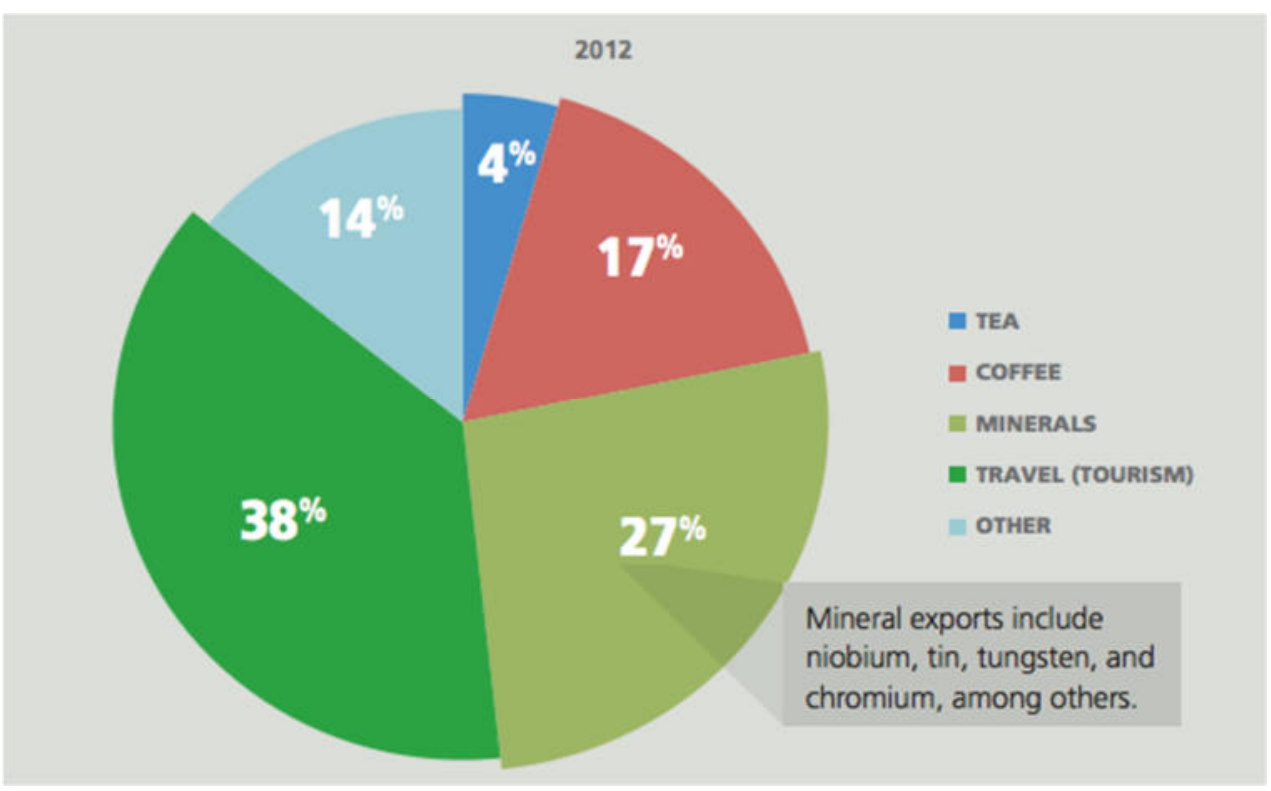

Source: Calculations based on WDI data, and COMTRADE mirror import data.

\subsection{Tanzania}

Tea in Tanzania is mainly grown in five regions namely Mbeya, Iringa, Njombe, Kagera and Tanga. By controlling the prices of tea, the Tea Board of Tanzania (TBT) has been very successful in raising the tea production by focusing on supporting the small-scale farmers.

Tea Board of Tanzania (TBT) is also organizing events, promotions and other marketing activities both in Tanzania and abroad to market the tea commodities produced by small farmers. Like other East African countries, Tanzania is also selling around 5,000 to 8,000 tonnes of tea at Mombasa tea auction every year.

Figure 7: Tanzania Exports of Coffee, tea, mate, and spices

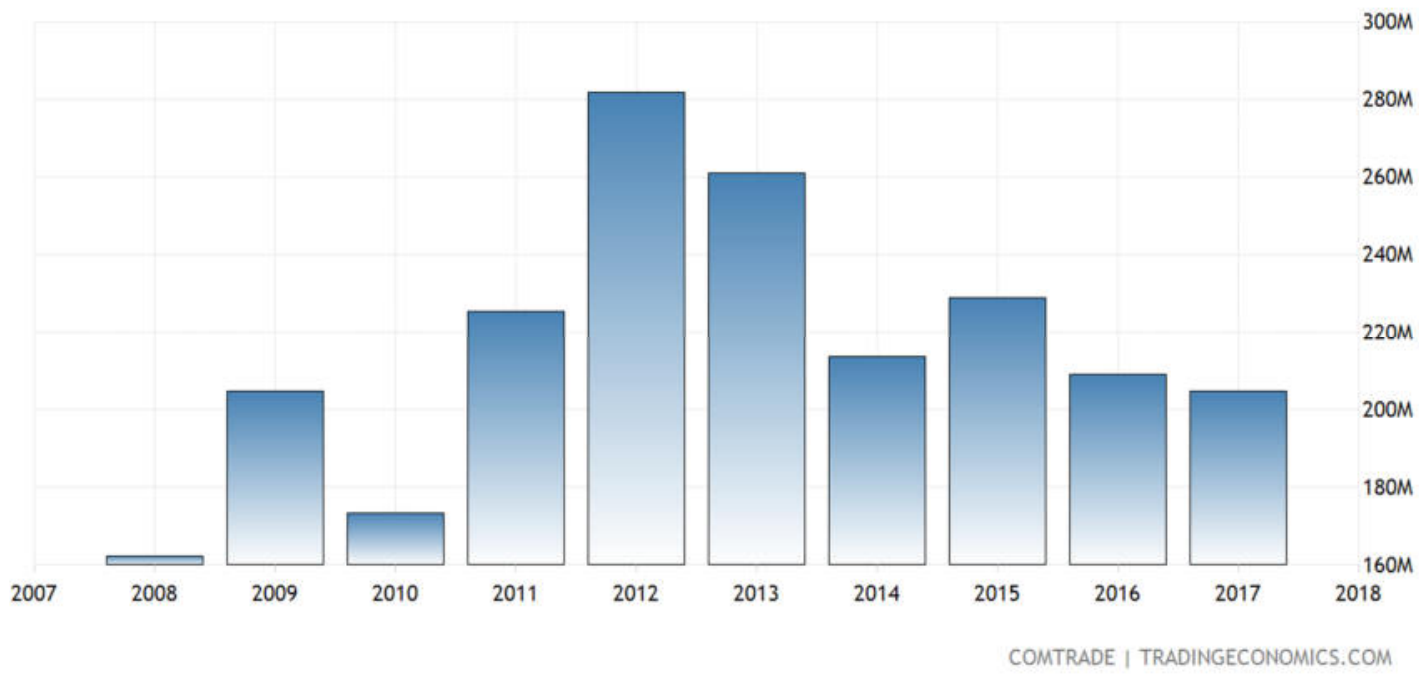

Source: Comtrade 
Another advantage that the Tea Board of Tanzania is doing to small-scale farmers in offering transport and warehouse storage facilities. Also some tea processors like world known Unilever Tea has invested \$8 million tea processing Plant in Mufindi, Tanzania.

Tanzania Exports of Coffee, tea, mate, and spices was US\$204.53 Million during 2017, according to the United Nations COMTRADE database on international trade, see figure 7.

\subsection{Conclusion}

The east African tea industry is having great potential for the future. However, the region has to overcome the challenges related to black tea production and production efficiencies.

Further, when moving forward, it is a must to explore the possibilities for black tea value addition like iced tea in home countries as well, a large portion of the profit share remains with the ultimate packer or trader.

The East Africa region has to focus on identifying changing trends in the consumer market instead of sticking to the age-old production and trading techniques. For instance, the demand for sustainable initiatives such as organic production and fair trade production is rising all over the world, and this region has massive potential in capitalizing on these untapped areas.

\section{Acknowledgment}

The author acknowledges the academic support of Professor Song Wei, Dean School of Public Affairs of the University of Science and Technology of China. The author also would like to give a word of thanks to Professor Song for his commitment to tea culture and expertise.

\section{Conflicts of Interest}

The authors declare no conflict of interest.

\section{The Data Availability Statement}

The data used to support the findings of this study are available from the corresponding author upon request.

\section{Source of Funding}

The author would like to mention The Third World Academic of Science (TWAS) and the Chinese Academy of Science (CAS) for their financial support during this research work.

\subsection{References}

1. A novel technology for the production of instant tea powder from the existing black tea manufacturing process, Elsevier: Innovative Food Science \& Emerging Technologies, Ch.Someswararao, and P.P.Srivastav. Volume 16, October 2012, Pages 143-147

2. An International Tea Trade Policy for East Africa: An Exercise in Oligopolistic Reasoning, Research in Agricultural and Applied Economics, Dan M. Etherington

3. An Outlook of Rwanda's Export Performance, The World Bank, 2012. Research series No. 119: Uganda's Tea Sub-Sector: A Comparative review of trends, Challenges and Coordination Failures, Economic Policy Research Centre (EPRC) Munyambonera F. Ezra Corti and Paul Lakuma Madina Guloba - September 2014

4. Black Tea: Health Uses and Risks - WebMD. https://www.webmd.com/vitamins-and-supplements/blacktea-uses-and-risks

5. Chai ya Tangawizi (Kenyan Ginger Tea), by Tara - Tara's Multicultural Table

6. $\quad$ East African Countries: List of Countries in East Africa, Answers Africa

7. FAO. 2015. Analysis of price incentives for tea in Malawi. Technical notes series, MAFAP, by Cameron, A., Mkomba, F., Rome.

8. For the love of African teas, Voices of Africa 2014.

9. Journal article: Huston J.A, 1978, An outline of the early history of the tea industry in Malawi, The Society of Malawi Journal, Vol. 31, no. 1 (January 1978), pp. 40-46

10. Kenya's tea export earnings, output seen rising in 2018, Reuters. Nairobi 2018

11. MAAIF (2012). Operationalization of the non- ATAAS component of the development strategy and investment plan: Draft analytical report on the tea value chain

12. Malawi Economic Snapshot H2, 2017, KPMG 
13. Perfect Insider, Nisha 2015

14. Standard Chartered's Socio-Economic Impact in East Africa, Standard Chartered Bank Kenya Limited. Steward Redqueen 2017

15. Uganda's tea production to increase by 2018, By Dorothy Nakaweesi Daily Monitor, SEPTEMBER 11 2012

16. The agriculture sector in Kenya, FAO

17. Tea and Coffee Industry in Kenya 2005, Export Processing Zones Authority

18. Tea sector, CTA Publications 2013

19. Rizwan, A., Zinchenko, A., Özdem, C. et al. Clin Phytosci (2017) 3: 13. https://doi.org/10.1186/s40816-017-0049-4

20. Tea Processing Chart by Tony Gebely is licensed under a Creative Commons Attribution-NoDerivs 3.0 Unported License. Based on a work at worldoftea.org.

21. Tea Exports by Country, World Top Exports WTEx Daniel Workman 2018

22. Tea Producing Regions of the World - Africa; Beverage Standard Association (BSA), Hampshire, UK 2010

23. The map of East Africa region, WIKIMEDIA Commons 2018 by Maphobbyist

24. The World's Largest Black Tea Exporter, USDA Foreign Agricultural Services by Brian Dutoi, Nairobi 2013

25. The Tea Detective, Uncovering and Exploring the Facts About Tea http://theteadetective.com/TeasOfMalawi.html

26. Trading Economics, Tanzania Exports of Coffee, tea, mate and spices available at https://tradingeconomics.com/tanzania/exports/coffee-tea-mate-spices

27. The Teas of Malawi - Africa's Second Largest Tea Producer, The Tea Detective 